\title{
The modification of EVA resins for photovoltaic encapsulants
}

\author{
Weilu ZHANG ${ }^{1,2, a}$, Yajie Kong ${ }^{1, b}$, Zhimin $\mathrm{Qi}^{1, \mathrm{c}}$, Dong ZHANG ${ }^{1, \mathrm{~d}^{*}}$, Jie REN ${ }^{2, \mathrm{e}}$, \\ Xiangji JIANG ${ }^{3, f}$, Xuemei ZHOU ${ }^{3, g}$, Huaidong $\mathrm{JIN}^{3, \mathrm{~h}}$ \\ ${ }^{1}$ Institute of Applied Chemistry, College of Chemistry and Materials Engineering, Wenzhou \\ University, China \\ ${ }^{2}$ College of Chemical Engineering, Zhejiang University of Technology, China \\ ${ }^{3}$ RuiYang Photovoltaic Material Co.,Ltd, Zhejiang Zhongli Group, China

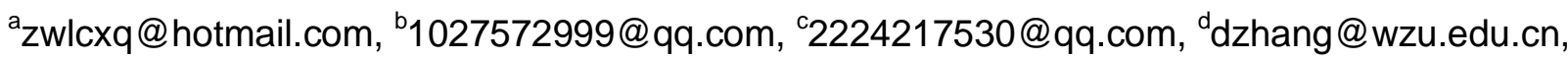 \\ erenjie.r@263.net, \\ fjxj@revax.cn, ${ }^{9} x u e m e i @ r e v a x . c n,{ }^{h}$ jhuaidong@revax.cn
}

*Corresponding author: Dong ZHANG, dzhang@wzu.edu.cn, +086 57786689510

Keywords: PV; Encapsulant; EVA; Modification; Film.

\begin{abstract}
The ordinary poly(ethylene vinyl acetate) (EVA) resin can't meet the requirements of encapsulating photovoltaic (PV) modules, so the service life of them has not been prolonged for 25 years. The chemical modifications of EVA were studied in this paper to improve the properties of PV encapsulants. It was found that the performance such as transmittance, volume resistivity, peel strength, and thermostability were increased after modifications.
\end{abstract}

\section{Introduction}

Although with good melting fluidity, low melting temperature, and hot melting adhesion, EVA resin still has some disadvantages, for example, poor heat resistance, low cohesive strength, poor creep resistance and expansion and contraction. ${ }^{[1]}$ To meet the requirements of encapsulants for PV modules, chemical modification was mainly adopted, namely, the addition of cross-linking agents. ${ }^{[2]}$ At certain temperature, they will be decomposed and generated free radicals which further triggered the bonding among EVA molecules, and three-dimensional network structure formed finally. When the degree of cross-linking is over $60 \%$, there are no expansion and contraction found in EVA film. Moreover, unsaturated bonds in EVA molecules will be destroyed by ultraviolet light, and crack, degradation and discoloration, and adhesive failure maybe occurred. ${ }^{[3,4]}$ These problems can be solved by ultraviolet light stabilizer. ${ }^{[5,6]}$ So the chemical modifications by crosslinking agents, light stabilizer and other auxiliaries, the hot melting, adhesive strength, photo-stability and aging 
resistance of EVA resins could be greatly improved in order to meet the requirements of preparing PV encapsulants. ${ }^{[7,8]}$

\section{Experiments}

\section{Materials}

EVA resins were brought from Dupont Corporation. Antioxygen, crosslinking agent, and coupling agent were commodity and not purified before used.

\section{Preparation of PV encapsulants samples}

R1, R2, R3 and R4 (Rs) were the films made by EVA resins only. E1, E2, E3 and E4 (Es) were the corresponding PV encapsulants (PVEns) prepared with the same EVA resins, antioxygen, crosslinking agents and coupling agents according to the proportion, respectively. All of the components were mixed by a high-speed mechanical mixing ( $2000 \mathrm{rpm}$ for $30 \mathrm{~min})$. Afterwards, the mixture was fed into a film machine, and the PVEns samples were manufactured following by melt, outflow, air-cooled and stretch.

The photology, electricity, mechanics and heat stability of the two kinds of films were analyzed according to GB/T 29848-2013.

\section{Results and discussion}

\section{PVEns' Physical Properties}

\section{Transmittance}

The transmittance of the two kinds of films was shown as Figure 1. The transmittance of all of the encapsulants Es were improved after the modification of Rs.

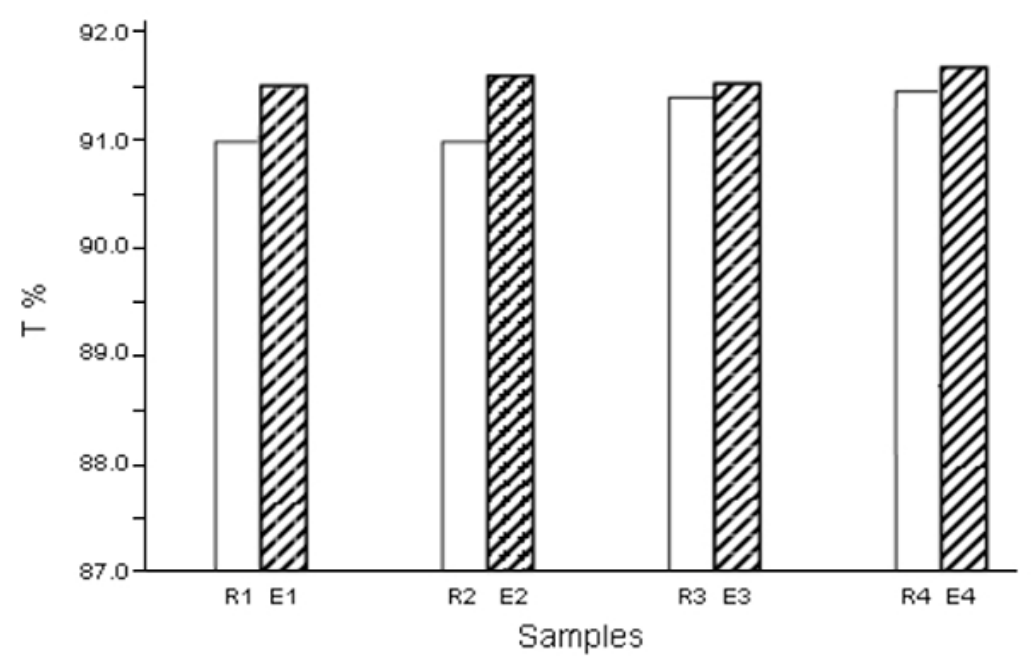

Fig. 1 Transmittance of Rs and Es

\section{Volume resistivity}

The volume resistivity (VR) changed after modification which was shown as Figure 2. It could be 
seen that VR of all of Rs was decreased by one magnitude order compared with Es. Free ions were the major factor of polymer's conduction. These ions mostly came from the initiating agents, impurity of raw materials, and addition agents in the process of synthesis.

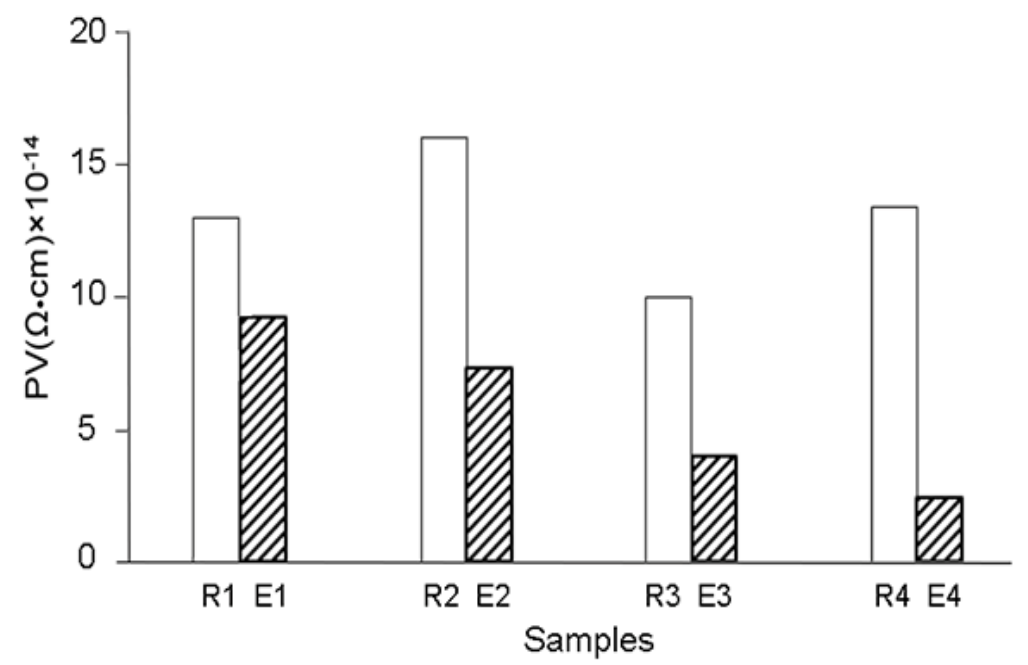

\section{Peel strength}

Fig. 2 Volume resistivity of Rs and Es

As shown in Figure 3 and Figure 4, peel strengths of Es with glass (PS-g) and with TPT (Tedlar+PET+Tedlar) backplant were all greatly improved after modification. When cross-linking agents and coupling agents were added, the cross-linking degree improved and formed three-dimensional network structure which enhanced tensile stress resistance and mechanical strength. Moreover, the addition of agents increased the fluidity of melt adhesive and viscosity, which further enhanced the peel strength.

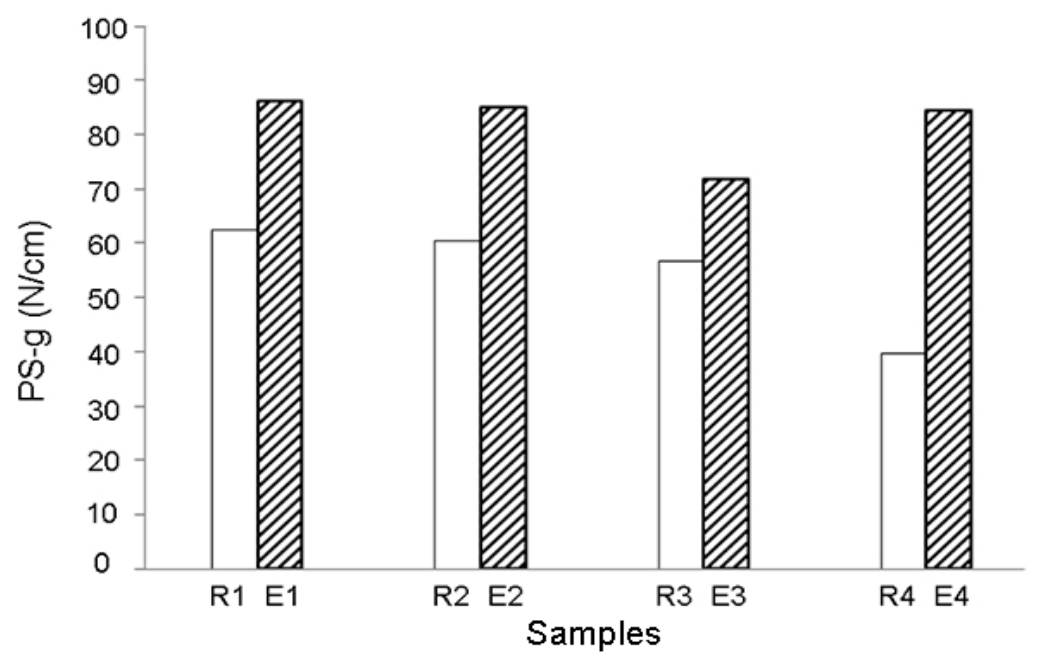

Fig. 3 Peel strength of Rs and Es with glass, respectively

\section{PVEns' Thermostability}

The thermogravimetric temperature of $\mathrm{R}$ and $\mathrm{E}$ samples in the first stage was $250 \sim 400^{\circ} \mathrm{C}$, which was the decomposition of acetic radical groups in EVA, and the second stage $425 \sim 500^{\circ} \mathrm{C}$ of the 
decomposition of ethylene chains. The thermogravimetric temperature of Es samples was higher than that of Rs samples, which maybe resulted from the three-dimensional network structure.

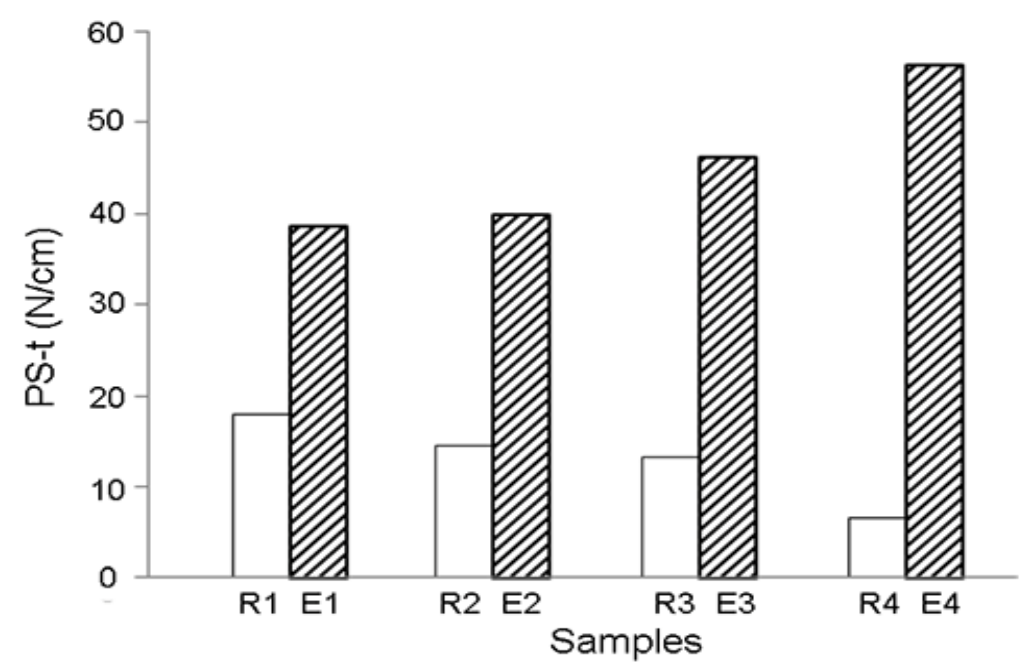

Fig. 4 Peel strength of Rs and Es with TPT, respectively.

\section{Summary}

The EVA resins were modified by auxiliaries such as crosslinking agents, coupling agents, and the films were prepared and analyzed according to China Standard of GB/T 29848-2013. The results indicated that the properties of Es were improved by the modifications, which met the needs of encapsulating PV modules.

\section{Acknowledgments}

This research was financially supported by Public Projects of Zhejiang Province (014C31008) and Public Projects of Wenzhou City (G20140043).

\section{References}

[1] M. Kharazi, L. Kullman, C.G. Granqvist, Solar cells, Sol. Energ. Mat. Sol. C. 53 (1998) 349-356.

[2] D.H. Yao, B.J. Qu, Q.H. Wu, Photoinitiated crosslinking of ethylenevinyl acetate copolymers and characterization of related properties, Polym. Eng. Sci. 47 (2007) 1761-1767.

[3] P. Klemchuk, M. Ezfin, G. Lavigne, Investigation of the degradation and stabilization of EVA-based encapsulant in field-aged solar energy modules, Polym. Degrad. Stabil. 55 (1997) 347-365.

[4] G. Oreski, G.M.Wallner, Evaluation of the aging behavior of ethylene copolymer films for solar applications under accelerated weathering conditions, Sol. Energ. 83 (2009) 1040-1047.

[5] F.J. Pern, Factors that affect the EVA encapsulant discoloration rate upon accelerated exposure, Sol. Energ. Mat. Sol. C. 41 (1996) 587-615.

[6] F.J. Pern, S.H. Gliek, Photothermal Stability of encapsulated Si solar cells and encapsulation 
materials upon accelerated exposures, Sol. Energ. Mat. Sol. C. 61 (2000) 153-188.

[7] H.A. Khonakdar, S.H. Jafari, A. Haghighi-Asl, Thermal and mechanical properties of uncrosslinked and chemically crosslinked polyethylene/ethylene vinylacetate copolymer blends, J. Appl. Polym. Sci. 103 (2007) 3261-3270.

[8] A.W. Czanderna, F.J. Pern, Encapsulation of PV modules using ethylene vinyl acetate copolymer as a pottant: A critical review, Sol. Energ. Mat. Sol. C. 43 (1996) 101-181. 